\title{
Lupus Pernio-A Rare Case Report
}

Uddin $\mathrm{M} \mathrm{J}^{1}$, Huda $\mathrm{S} \mathrm{M}^{2}$, Rahaman $\mathrm{M} \mathrm{M}^{3}$, Siddique $\mathrm{R} \mathrm{U}^{4}$, Islam $\mathrm{M} \mathrm{A}^{5}$

\begin{abstract}
Lupus Pernio is a chronic form of Sarcoidosis and it is a poor prognostic factor. It is commonly associated with bone cyst and pulmonary fibrosis. Spontaneous remission is rare. On this occasion we are reporting a case of 25 year old lady presented with a well defined erythematous plaque on the tip of the nose for last 8 years without any associated findings.

\section{Introduction}

Sarcoidosis is a multisystem granulomatous disease of unknown cause. The lung is the most commonly affected organ, but the skin is frequently involved.Sarcoidosis has been comprehensively defined by Scadding and Mitchell as an idiopathic multisystem disease characterized by formation of non caseating epithelioid cell tubercles in affected tissues or organs ${ }^{1}$. The disease process is generalised, with various manifestations and unpredictable course. Between 20-35\% of patients with systemic sarcoidosis have cutaneous manifestations, but cutaneous sarcoidosis can also occur without systemic disease in about $25 \%$ of cases ${ }^{2}$. It is more common in developed countries and uncommon in our country. Here we present a case of cutaneous sarcoidosis(lupus Pernio) with no systemic manifestations.
\end{abstract}

\section{Case report}

A 25 year old female presented to dermatology out patient department in BSMMU with a solitary,asymptomatic well defined erythematous plaque on the tip of the nose for last 4 years. There was no history of loss of weight, fever, cough, breathlessness, palpitations, chest pain, eye complaints, arthritis or arthralgia, or urinary symptoms. No history of trauma, discharge from the lesion, loss of sensation or weakness of limbs. Dermatological examination revealed a well defined erythematous plaque involving the tip of the nose (Fig-1 and 2). There was no hypoesthesia or peripheral nerve thickening. Investigations revealed normal hemoglobin with slightly raised $\operatorname{ESR}(35 \mathrm{~mm})$. Mantoux test showed $5 \mathrm{~mm}$ of induration. Liver function and renal function tests were normal. Chest X-ray showed no abnormality. Serum calcium and ACE levels were normal. Skin biopsy taken from the lesion showed scattered, discrete, non-caseating, epithelioid granulomas (Fig-3). These granulomas were naked i.e. they lacked lymphocytes in the periphery. Granulomas also consisted of giant cells (Fig-4).

1 Corresponding Author: Dr. Mohammad Jamal Uddin Assistant Professor, Department of Dermatology and Venereology Bangabandhu Sheikh Mujib Medical University jamalbsmmu@yahoo.com

2 Professor (Brig.Gen) Md. Shamsul Huda Professor \& Former Head, Department of Dermatology Combined Military Hospital, Dhaka

3 Dr. Md.Mahabubur Rahaman Consultant, Dermatology \& Venereology Comilla Medical Center, Comilla

4 Dr. Md.Rahamat Ullah Siddique Research assistant, Department of Dermatology Bangabandhu Sheikh Mujib Medical University

5 Dr. Md.Aminul Islam

Assistant professor, Department of Dermatology Northern medical college

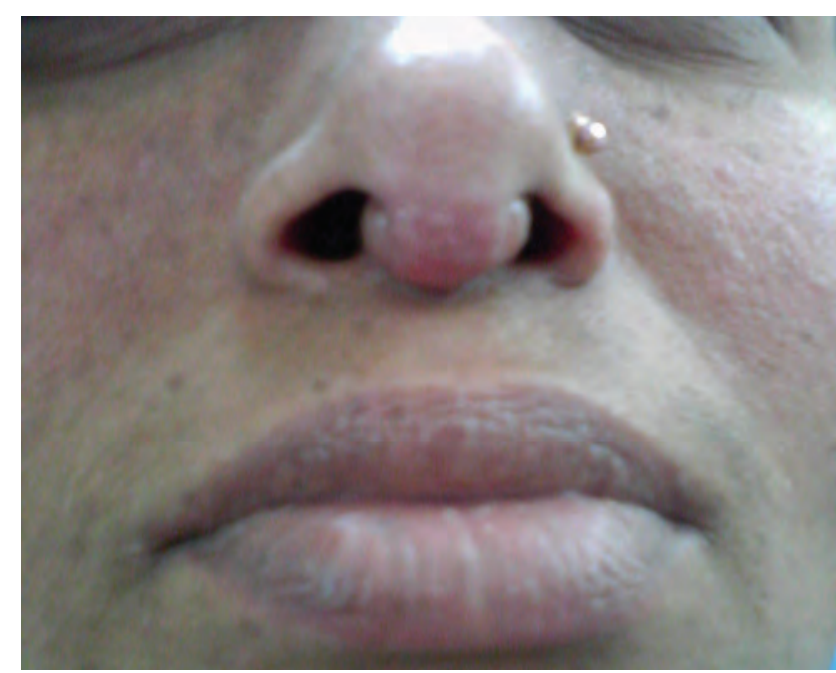

Fig:1-A well defined reddish plaque on tip of the nasal septum

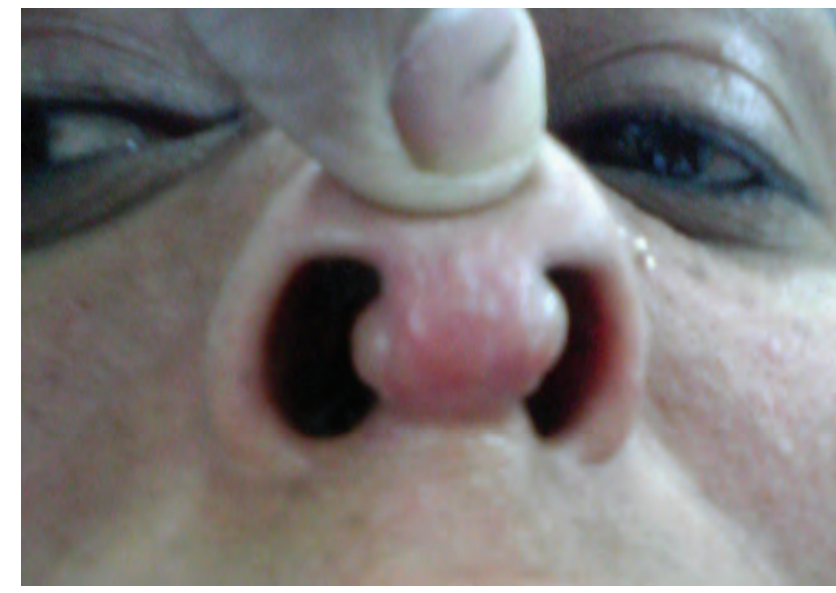

Fig:2-Close view showed a well defined erythematous plaque on tip of the nasal septum

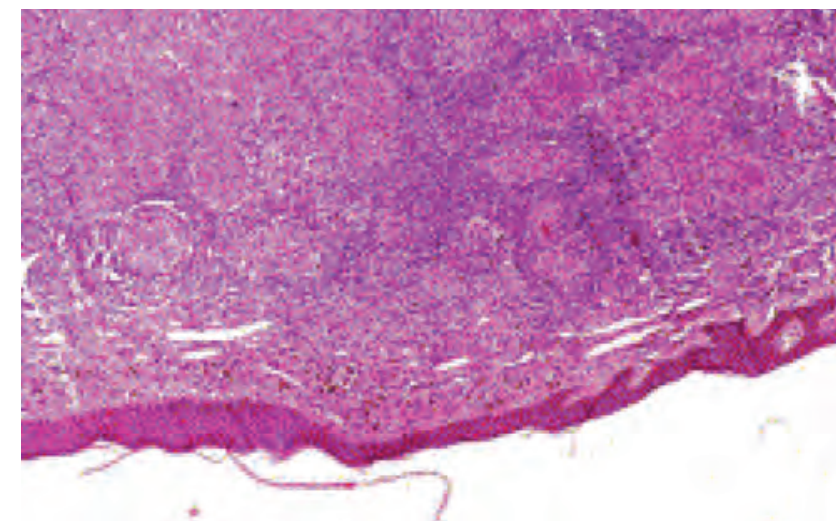

Fig:3- HE $\times 40$ showing scattered discreet granuloma with no necrosis 


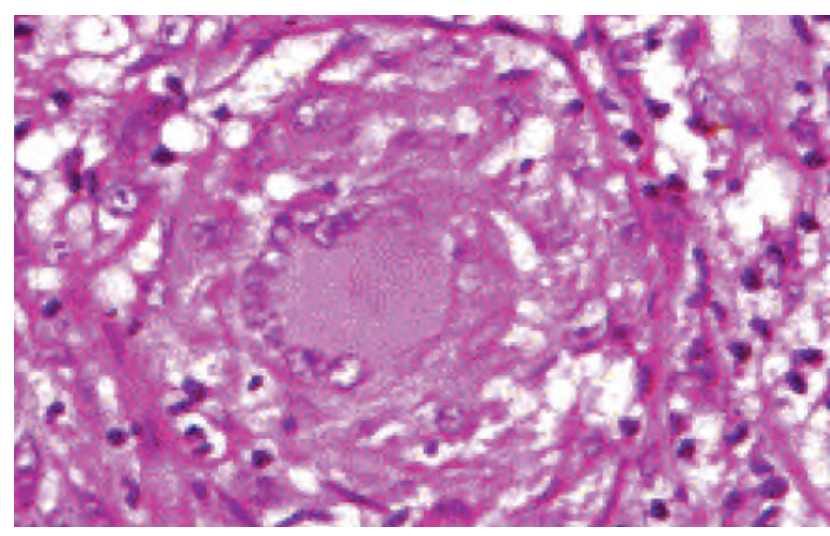

Fig:4- HE $\times 400$ showing a giant cell.

\section{Discussion}

Sarcoidosis is the result of an immune dysfunction due to a persistent antigen of low virulence that is poorly cleared by the immune system. Cutaneous lesions of sarcoidosis are classified into non specific and specific types. Non specific manifestations present as erythema nodosum, erythema multiformae, calcinosis cutis or nummular eczema. Specific types are classified as maculopapular, papular (lichenoid), nodular (annular, angiolupoid, subcutaneous), plaque (lupus pernio) and erythematous types depending on the type and extent of involvement of the skin and subcutaneous tissues. Unusual and atypical forms are atrophic, ichthyosiform, erythrodermic, ulcerated, verrucose, etc. are also known to occur ${ }^{3}$. Ocular involvement in sarcoidosis is most often in the form of uveitis. Eales disease is an idiopathic obliterative vasculopathy usually involving the peripheral retina and is not a manifestation of sarcoidosis ${ }^{1}$. Sarcoidosis needs to be distinguished histopathologically from lupus vulgaris and leprosy as they all have epithelioid cell granulomas. While the granulomas in lupus vulgaris are caseous and present in the upper dermis, those in leprosy are mainly around dermal nerve twigs and admixed with abundant lymphocytic infiltration. In contrast, sarcoidal granulomas are discrete, distributed uniformly in the dermis and surrounded by sparse lymphocyte cuffing ('naked tubercles'), with fine reticulin fibers in and around the tubercles". Serum ACE is derived from epithelioid cells of the granulomas and reflects the granuloma load in the patient. Serum ACE levels are neither diagnostic nor predictors of systemic involvement. It is elevated in approximately $60 \%$ of patients and is useful in monitoring the clinical course of the disease ${ }^{5}$. Gallium-67 scintigraphy is a sensitive method to demonstrate systemic involvement as it is rapidly taken up by the cutaneous lesions, salivary glands, lacrimal glands and intrathoracic lymph nodes ${ }^{6}$.

However this facility may not be available everywhere and the test is expensive to perform. Though numerous modalities of treatment are mentioned in literature, no consistently effective treatment of sarcoidosis exists ${ }^{7}$. Early treatment of cutaneous sarcoidosis is essential in order to prevent permanent scarring of the skin. A conservative approach Fig. 3: Sarcoidal granuloma (H \& E stain X 100 ) Fig. 4: Lupus pernio on the nose after treatment is usually followed except for those with systemic manifestations. Chronic cutaneous lesions like lupus pernio and those that may cause scarring also require immunosuppressive therapy for long periods ${ }^{8}$. Oral hydroxychloroquine, levamisole, allopurinol or colchicines can be used as steroid sparing agents in some cases ${ }^{9}$. In our case, we could achieve rewarding results by selective administration of oral prednisolone. The clinical silence of sarcoidosis precludes an accurate prognosis, as it depends on the extent and severity of systemic involvement. Though cutaneous involvement in sarcoidosis may occur at any stage of the disease, it commonly occurs at the onset. Spontaneous remissions are known to occur. However, in a recent study $30 \%$ of cases reporting with initial specific lesions of cutaneous sarcoidosis later developed systemic involvement ${ }^{10}$. This case highlight a purely cutaneous presentation of a protean and uncommon disease. A long term follow up is imperative to look for systemic involvement if not demonstrated initially.

\section{References}

1. Scadding JG, Mitchell DN. Sarcoidosis. 2nd ed. London: Chapman and Hall, 1985

2. Hano R, Needelman A, Eiferman RA, Callen JP. Cutaneous sarcoidal granulomas and the development of systemic sarcoidosis. Arch Dermatol 1981;117:203-7

3. Gawkrodger DJ. Sarcoidosis. In: Champion RH, Burton JL, Burns DA, Breathnach SM, editors. Textbook of Dermatology. 6th ed. London: Oxford Blackwell Science, 1998;2679-702

4. Lever WF, Schamberg-Lever G. Histopathology of the skin. 7th ed. Philadelphia: Lippincott, 1990;252-6

5. Callen JP, Hanno R. Serum angiotensin I converting enzyme level in patients with cutaneous sarcoidal granulomas. Arch Dermatol 1982;118:232-3

6. Huisman PM, Van Royen EA. Skin uptake of Gallium 67 in cutaneous sarcoidosis. Acta Derm Venereol 1985;65:243-7

7. Karrer S, Abels C, Wimmershoff MB, Landthaler M, Szeimies RM. Successful treatment of cutaneous sarcoidosis using topical photodynamic therapy. Arch Dermatol 2002;138:581-4

8. Wilson NJ, King CM. Cutaneous sarcoidosis. Postgrad Med J 1998;74:649-52

9. Baughman RP, Lower EE. Steroid-sparing alternative treatments for sarcoidosis. Clin Chest Med 1997;18:853-64

10. Mana J, Marcoval J, Graells J, Salazar A. Cutaneous involvement in sarcoidosis: relationship to systemic disease. Arch Dermatol 1997;133:882-8 